\title{
Regional and Urban/Rural Differences of Public Health in China
}

\author{
Yuhui Li (Corresponding author) \\ Department of Sociology, Rowan University \\ 201 Mullica Hill Rd., Glassboro, NJ 08028, USA \\ Tel: 856-256-4500 ext. 3786 E-mail: li@rowan.edu \\ Linda Dorsten \\ Department of Sociology/Anthropology/Social Work/Criminal Justice \\ SUNY Fredonia, 280 Central Ave., Fredonia, NY 14063, USA \\ Tel: 716-673-3469Ｅ-mail: Linda.Dorsten@fredonia.edu
}

\begin{abstract}
This research studies public health in China between urban and rural sectors and among the three geographic regions of the coast, inland and west. Similar to the situation of many other countries, public health in China is affected by economic development levels and the extent to which economic resources are distributed equitably in the three regions. In addition, China's economic reform in the last three decades has brought about tremendous changes in social structure and institutional arrangements that we argue have had significant impact on health of the population in China as well. These structural changes include village-run industrial development in rural areas, the reform of state-owned enterprises in urban areas and the marketization of medical institutions.
\end{abstract}

Keywords: Public health, China, Regional development, Urban vs. rural differences

\section{Introduction}

It has long been suggested by researchers that health is one of the most valid indicators to evaluate a population's well-being and social stratification. Good health and health equity for all members of the society are often advocated by even those who tend to rationalize the stratification of economic measures such as income (Anand, 2006; Daniels, et al., 2006; Sen, 2006). On the other hand, most studies on community and societal stratification focus on economic development instead of health. Studies that do deal with health tended, until recently, to focus on medical and technical aspects such as health care delivery and access to medical facilities.

Researchers in recent years have argued that what is needed are multidimensional and multi-disciplinary approaches and frameworks that are inclusive enough to adequately address all relevant factors that affect health. The comprehensive methodologies and theories should reflect political, social and economic structures, public policy, cultural characteristics, and so on (Sen, 2006; Daniels et al., 2006). Along similar lines of argument, some researchers propose to shift our focus away from the approach that emphasizes a direct link between economy and health or between medical services and health, and instead adopt an "indirect" approach that takes into consideration the large picture that involves a complicated and interconnected set of variables and issues in the study of health (Peter, 2006). Research has shown, for example, that the socioeconomic status of individuals has an impact on their morbidity and mortality through a phenomenon referred to as relative deprivation. Those who suffer from poor health are not just the most disadvantaged or underprivileged, but also those who fall behind others within certain social contexts in social participation and economic gains (Siegrist, 2000; Marmot, 2006). This explains why health stratification persists even in the most economically advanced societies where basic needs for existence have been met for the vast majority of the population.

While emphasizing the approach of inclusiveness and comprehensiveness of relevant factors in the study of health, researchers also argue that we need to keep in mind the variations of patterns and dynamics of health-related characteristics of specific societies. Unique conditions of various populations and societies, as well as particular patterns of their relationship to health, need all to be taken into consideration (Adams, 2006; Robert, 1998; Wilson, 1987; Liu et al., 2001). China and the United States, for example, tend to have different patterns in the explanation of public health. While ethnic and racial characteristics are found to be significant determining factors of health in the United States, China's regional variation tends to play an important role in predicting its 
public health (Anand, 2006). Regional variations in China are in turn closely associated with the country's urban vs. rural sectors.

\section{Regional and urban vs. rural health inequality in china}

Increasing amounts of information and data on and from China have been made available since the beginning of the reform three decades ago, but health-related data are relatively scarce, particularly those of historical patterns and/or of specific relevance. For example, it was not until several years into the $21^{\text {st }}$ century that Human Development Index (HDI), of which life expectancy is a major component, was calculated separately for urban and rural residents for the first time ever for the population (China Human Development Report 2005, 2005).

In spite of the difficulties of obtaining official information on health and life in China, data that are gathered from various sources suggest that China has seen a continuous improvement in public health since the founding of the PRC. The average life expectancy in China was 35 when the PRC was founded in 1949 and it increased to 64 by 1980. It continued to improve in the next two decades and reached 68 in 1990 and then rose to 71.8 in 2000 (Riley, 2004; China Human Development Report 2005; China Statistical Yearbook 2007).

On the other hand, however, severe health inequity exists in China between urban and rural sectors and among regions and provinces. People living in urban areas have an advantage in life and health compared with those living in rural areas, and there is no exception to this pattern in all the 31 provincial-level administrative units. Urban residents on average live a life that is more than five years longer than rural residents with a life expectancy of 75.21 for the former and 69.55 for the latter, according to the 2000 Chinese census (Table 1).

Regional health inequity is also severe in China and it seems to have an interacting relationship with the urban vs. rural health inequity discussed above. Data in Table 1 show that the coastal region is a much healthier region with a life expectancy of 75.31, as opposed to that of 72.74 and 69.67 respectively in the central and western regions. Furthermore, the urban-rural health discrepancy widens progressively from the coastal to central and to the western regions. In the coastal region, there is a 3.39 year difference ( 77.03 vs. 73.64$)$ of life expectancy between urban and rural dwellers. In the central and western regions, the differences become 4.6 (76.1 vs. 71.57) and 7.92 (76.03 vs. 68.11) respectively. That is to say, the urban-rural difference in life expectancy in the western region is more than twice as severe as that in the coastal region. An average resident in Shanghai, a coastal city with a life expectancy of 79.36 years, is expected to live a life that is more than fifteen years longer than an average resident in rural Tibet, a provincial-level area in the western region with a life expectancy of 64.34 !

The inequity of health between urban and rural areas and among regions is reflected in not only average life expectancy for the general population, it is also shown in other aspects of public health, such as the health of children and women. According to the China Human Development Report (HDR) commissioned by the United Nations Development Program (UNDP), infant mortality rate (mortality of children one year old or younger), as well as mortality rate for children of five years old and younger, in rural areas were both nearly three times as high as those of urban areas in China. In addition, maternal mortality in rural areas is twice as high as that in urban areas. Again, children's and women's health inequity seems to vary from region to region according to regional differentiations of population health discussed above. For example, the HDR shows that the rates of malnourished (e.g., underweight and stunting) children in the western region is twice as high as that of the coastal region (China Human Development Report 2005).

\section{Explanation of health inequalities in china}

\subsection{Historical Patterns}

Consistent with observations of many other countries, the regional and urban vs. rural health inequity in China is closely associated with China's uneven distribution of economic and social resources. Urban areas and the coastal region in China have enjoyed a higher standard of living and experienced a more advanced level of economic development, and the pattern of imbalanced economic and social development could be traced to the pre-PRC eras.

When the PRC was founded in 1949, it inherited economic and social infrastructures that were extremely uneven in favor of the coastal region, where most of China's cities were located at the time. The imbalanced economic and urbanization patterns were further aggravated after 1949. During the first three decades of the PRC, the Chinese government adopted a strictly centrally-planned policy that emphasized the development of industrial production and urban areas over other aspects in the national economy. As a result, rural areas and agriculture, particularly those in inland and remote western regions, were often neglected or even exploited in order to 
sustain the urban and industrial development of the country. These policies further deepened the urban-rural divide and regional differences.

Since the reform that started three decades ago, China has been experiencing an average rate of economic growth of ten percent, which is considered by many as the most dramatic economic gain in human history (e.g., Restall, 2008). Thanks to such remarkable economic achievements, China has been ranked the fourth largest economy in the world since at least 2005. The progress and economic gains in China, nonetheless, are achieved at the expense of rapidly escalating economic and social divisions between urban and rural areas and among geographic regions, as has been intensely discussed in the literature (e.g., Yao, et al., 2004; Wu, 2002; Fan and Sun, 2008). Furthermore, we argue that the economic inequalities have brought about growing discrepancies in opportunities for citizens to realize their aspirations and to enhance their personal and public health and wellbeing. Our discussion in the next section will focus on two aspects of the reform that we suggest have generated significant and far-reaching consequences to the Chinese society, particularly in the health of China's population. One aspect is the change of non-agricultural production and employment in rural areas and the other one is the reform of state-owned industries in urban areas.

\subsection{Changes Due to Reform Policies}

\subsubsection{Change of rural economy and employment structure in China}

China is still a rural country with an average urbanization level of 43.9 percent. There is a wide range of variations in the urbanization levels among regions and provinces. Without considering the four provincial level municipalities, the province with the highest urbanization level in China is Guangdong with 63 percent urban population in 2006. At the bottom of the scale of urbanization level are two provinces both in the western region: 27 percent in both Tibet and Guizhou. The urbanization levels of the coastal, central and western regions were 53, 35 and 28 in 2000 and they changed to 61, 42 and 37 percent respectively in 2006 (China Statistical Yearbook, 2001 and 2007).

During the rigidly planned economy of the first three decades of the PRC, rural areas were designated mainly as the site for food production and for supplying raw materials for industrial production that took place solely in urban areas. With the collapse of the collective commune system and the privatization of agricultural production at the beginning of the reform, increasing numbers of rural villages were facing the problems of shortage of land and excessive labor power, and therefore started to establish industries and non-agricultural businesses to absorb excessive labor and improve their economy. Competing with existing industrial facilities that had been mostly state-owned until the reform, these village-run businesses tended to be flexible and efficient, investing in productions demanded by the market but companies owned by the state had either neglected or did not care to be involved in. Within a few years after the reform, village-run industries and businesses became so successful that their products constituted a major component in China's economy. By 1991, nearly thirty percent of China's export commodities were produced by village-run industries (Song, 2008).

Farmers soon realized that pursuing non-farm jobs and businesses was the most desirable and effective approach, in some places it was the only approach, to increase their income and improve their conditions. The financial resources generated through booming village-run industries helped individual farmers, as well as local and regional communities, to enhance their quality of life, to improve the physical infrastructure, to build schools and medical facilities, to establish social welfare, in a word, to create a more civilized social and physical environment.

The coastal region in China saw the earliest village-run industries and has experienced the most drastic economic boom brought about by them. Employment statistics provide evidence for this assertion. Data in Table 2A show that since the 1990s, the coastal region has had a significantly more advanced industrial development owned and managed by villages and townships compared with the other two regions. The regional gap in terms of village and township-run industrial development seemed to have narrowed during the 2000s compared with the 1990s, although there was still a significant difference. The proportion of labor force employed in village and township industrial enterprises in the coastal region was three and a half times as high as that in the western region in 1997 and this ratio decreased to less than three in 2004. On the other hand, while less than half (41.61 percent) of rural employment is still engaged in agriculture in the coastal region, the percentage of rural employment in agriculture was 64.54 and 70.73 in central and western regions respectively (China Statistical Yearbook, 2005).

\subsubsection{Restructuring of industrial economy in China}

The reform in China initially started in rural areas and resulted in fruitful outcomes, as was discussed above. Urban reform, on the other hand, turned out to be a much greater challenge with much more complexities. At the 
core of the difficulties was the reform of state-owned industrial enterprises, the backbone of China's industry since they contributed about 75 percent of China's industrial output value when the reform started in the late 1970s (Larus, 2005, p. 7). Under the planned economy in China, nearly all industries were controlled and owned by the state and they were all located in urban areas. In line with the philosophical orientations of socialist economies, these companies provided employees stable and equal incomes as well as comprehensive welfare and benefits such as employment security, housing, retirement pension and medical insurance. On the other hand, due to the lack of incentives and competition, state-owned companies were notorious for their ineffective management styles.

During the $14^{\text {th }}$ Party Congress in October 1992, the Chinese government decided to gradually and cautiously introduce reforms to state-owned industries. With the introduction of market forces and decentralization of power, directors and company heads were expected to be responsible for their companies' profits and losses. They were encouraged to implement policies to reward commendable professional performances and punish employees who failed to fulfill their specifically stipulated responsibilities. The reform policies also allowed for the corporatization of state firms to issue stocks to investors and hence diversify the firms' ownership composition.

With these changes, urban reform has been steadily moving forward in China in the last two decades with market forces playing an increasingly more important role in industrial and urban economies. The pace and extent of urban reform are very uneven, however, across regions and among provinces, which is not surprising since the depth and pace of reform of state firms required certain social and economic conditions that were not evenly available across regions. For example, to cope with the negative consequences brought about by the reform, most noticeably large-scale lay-offs, a system of support and welfare must be developed such as employment or re-employment training, educational improvement of the general population, unemployment compensation, etc.

Data in Table 2B show that the coastal, central and western regions vary greatly in their degree of urban and industrial reforms and the variation became much greater in 2006 compared with 2000. At least half the labor force in urban areas was employed in state-owned firms in all the three regions in 2000, but the variation among them was relatively small, with the employment in state-companies in the western region approximately 27 percent higher than that in the coastal region. By 2006, employment in state-owned companies decreased to less than 50 percent in all three regions, with the coastal region experiencing the most rapid drop, resulting in more than 50 percent higher level of state employment in the western region than that in the coastal region. While nearly half of urban employment was still in state enterprises in both the western and central regions, less than 30 percent urban employment was in state firms in the coastal region (China Statistical Yearbook, 2007).

\subsubsection{Regional Variation in Economic Performance}

As a result of the variation of the implementation of reform policies in both rural and urban areas discussed above, the coastal region demonstrates a much stronger economy compared with the central and western regions, particularly in recent years, measured in terms of GDP per capita and average income. Data in Tables 3 and 4 show that there was a continuous tendency of aggravation of differences of GDP per capita among the three regions over the last more than half a century. While both the volume and the share of the average GDP in the coastal region kept increasing, the share of GDP for the central and western regions kept decreasing from 1952 to 2006. The widening gap among the three regions in economic development levels has accelerated since the start of the economic reform. In 1978, the volume of the economy in the coastal region was nearly twice that of the western region. By 2006, this ratio became nearly three. Table 4 shows that the GDP per capita of 11,334 yuan in the coastal region was nearly two and a half times that of the western region of 4,687 yuan in the western region in 2000 .

Data in Table 4 also show that, consistent with studies conducted in other countries, it is not just the amount of money or wealth, but the way money and wealth are distributed, that are important determining factors of health (e.g., Wilkinson, 2002). Literature has shown that the degree of equality of the distribution of economic resources is positively related to population health. This argument is supported by data on China as well. The better health in the coastal region is associated with a relatively narrower income gap between urban and rural areas in that region. Urban residents earn higher income than rural residents in all of China's provincial level units, with an average ratio of 2.79 in 2000 and 3.3 in 2006, as is shown in Table 4. This urban-rural income discrepancy became increasingly larger from coastal to central and to western regions in both 2000 and 2006 and the gap accelerated in all regions from 2000 to 2006. The ratio of urban-rural income per capita in the three regions, in the order stated above, was 2.47, 2.50 and 3.33 in 2000 and it increased to 2.58, 2.92 and 3.77 respectively in 2006. 
There is no doubt that the urban-rural divide and the regional disparities in China, as was discussed above, constitute significant aspects of the country's institutional arrangements and economic and social policies. Recently there has been increasing numbers of studies that examine how such policies and institutional set-up are transcended into means and mechanisms that affect the population's well-being and health. In the following section, we examine some of the studies and present data to help shed further light on this issue.

\subsection{How Economic Indicator Are Transcended into Variations in Health}

\subsubsection{Variation in health care expenditure}

As the above discussion indicates, the growing discrepancies in the distribution of economic resources among regions and between rural and urban areas in China have intensified since the reform. The increased economic stratification has had a huge impact on all facets of Chinese society, with public health probably being most negatively affected, which means a giant step backward from the impressive gains that China had achieved in the enhancement of public health during the first three decades of the PRC.

Prior to the reform, China had an international reputation for its socialist health care system enjoyed by all citizens in both urban and rural areas. Urbanites were covered under health care insurance of either Government Employee Insurance Scheme (GIS) or the Labor Insurance Scheme (LIS). The GIS was financed by governmental agencies and the LIS by enterprises and companies. In rural areas, the extensive medical system, known as Cooperative Medical Scheme (CMS), was funded by collective communes and staffed mainly by "barefoot doctors" who delivered medical service and vaccination from door to door in rural communities (Liu, et al., 2002).

Since the reform, however, health care services and medicine changed from those of social welfare to fee-for-service entities that became increasingly privatized, especially in rural areas. Hospitals and other medical facilities were expected to be self-dependent for their own financial operations. For example, recent studies have shown that the sale of drugs constitutes the largest income component in many hospitals in China and the proportion of this source as the major financial revenue has been steadily increasing since 1980 (Bloom and Tang, 2004; Anson and Sun, 2005).

At the same time, however, the share of the governmental spending on health care declined rapidly. The total health expenditure by the government dropped from 36.4 percent in 1980 to 15.5 percent in 1998 but the total out-of-pocket expenditure of health by individuals and families increased from 23.2 percent to 57.8 percent during this time period (Liu, et al., 2002). Not surprisingly, the reduced governmental spending on health varied with the coastal region and urban areas receiving a higher share compared with the inland and coastal regions and with rural areas. According to a recent report by the World Bank, the per capita governmental spending on health ranged from 360 yuan in Beijing to less than 50 yuan for many of the inland and western regions. This pattern is closely associated with a sharp difference in infant and child mortality rates in the three regions with those of the western region significantly higher than those of the coastal region (Wagstaff, et al., 2009; Anson and Sun, 2005).

With decreased governmental spending on health and unequal distribution of economic resources, it would be difficult for areas and regions with insufficient funds to invest in projects or facilities to enhance public health. Clean water and sanitary toilets, two of the basic conditions that have been linked to the significant reduction of spread of infectious diseases and that are taken for granted in cities in China, are unavailable in many parts of rural China. Data in Table 4 show that the availability of running water and sanitary toilets is uneven in the three regions. Only 61 percent and 55 percent of rural population in China respectively have access to clean water and sanitary toilets. Close to 79 percent of the rural population in the coastal region had access to clean water, but this figure dropped to 51 percent for the rural population in the western region in 2006. The proportion of rural population who had clean toilets was 64 percent in the coastal region had but only 40 percent in the western region. In other words, rural population in the coastal region was more than fifty percent more likely to have clean water and clean toilets compared with the rural population in the western region.

\subsubsection{Affordability of medical care}

Consistent with the pattern of many other countries, research has shown that poor people in both rural and urban areas in China have poorer health compared with people with more financial resources (Anson and Sun, 2005; Bloom and Tang, 2004). Logically this would mean poor people would have greater need for medical help. However, studies have shown that the utilization rate of medical facilities and services is lower by poor people compared with that by financially better-off individuals. Since poor regions and areas have a higher 
concentration of poor people, utilization of medical service in poor regions is lower compared with regions with higher levels of economic development in China (Anson and Sun, 2005; Bloom and Tang, 2004).

The fundamental reason for the above phenomenon, authors of the studies cited above point out, is a combined factor of the rising cost of medicine and health on the one hand, and the lack of medical insurance for the vast majority of rural population, as well as for many urban residents, on the other. The proportion of rural population that was covered by CMS dropped from ninety percent in 1979 to less than six percent ten years later in 1998 due to insufficient funding and support to the system (Liu, et al., 2002). With the collapse of the rural CMS, the majority of the rural population found they unable to cope with medical bills. Meanwhile, a large number of urban residents, particularly those who were unemployed, self-employed, retired, etc., also had to struggle financially when they fell ill.

The high cost of medicine was driven by the joint influence of marketization of medicine and health care and the steady growth of disposable incomes of the population in China (Anson and Sun, 2005). Since there is an extremely uneven distribution of income and wealth across regions and between urban and rural areas, as we discussed in the above sections, the affordability of medical cost also varies a great deal. According to data in Tables 1 and 4, urban residents could afford more financial expenses on medical and health-care services compared with rural residents in all the provincial level areas in China, but the gap of affordability of medical service widens in the three regions in the same pattern as the income gap discussed earlier. The ratio of medical and health-care expenses incurred by urban and rural residents in the coastal, central and western regions is 3.17 , 3.41 and 4.15 respectively in 2005. With an average ratio of 3.5, the urban-rural gap in health-care expenses in the 31 provincial level administrative units varies widely ranging from 1.4 in Shanghai to 7.6 in Tibet. That is to say, in 2005, while an average rural resident in Shanghai spent about 70 percent of what an average urban resident in Shanghai would spend on health care, an average rural Tibetan resident could afford only about 13 percent of what an average urban Tibetan resident would spend on health-care.

Research has shown that with the exception of the very poor, families and individuals in China that experience catastrophic illnesses are not driven into as dire a situation of absolute destitution as those in many other countries. This is due mainly to Chinese society's cultural pattern of social networking that provides financial and labor assistance to those who incur unexpected medical expenditures (Wilkes, et al., 1997). However, studies also show that when people in China could not afford the escalating medical cost, they tend to either ignore or self-treat health problems, both of which are obviously detrimental to health. It has been observed by several researchers, that the utilization of hospital beds in China decreased since the reform, and it stayed at around 74 percent in 2006 as the data in Table 4 show. What is important to point out is that the utilization of hospital beds in the western and inland regions is lower compared with that in the coastal region. This pattern, when combined with the finding about poor people's tendency to defer medical treatment discussed above, suggest that low utilization level of hospital beds in the western and inland regions was probably due to higher chance of inability by those in the western and inland regions to pay the medical costs. According to another study, among the patients who did get admitted into the hospital, 46 percent in urban areas and 60 percent in rural areas requested to be discharged against the advice of medical professionals due to financial reasons in 1998. In the poorest rural areas, this figure was as high as 80 percent (Liu, et al., 2002).

\section{Conclusion}

The notion that health is one of the most valid indicators of development was brought to a qualitatively more advanced level by Nobel Laureate Amartya Sen with his perception of the need for a broad and people-centered orientation in the study of developmental and welfare economics. Sen views health as an important prerequisite for developing and fulfilling human capabilities, which is defined as "people's ability to do and be what they have reason to value" (Sen, 1998; Sen, 2006). According to Sen, health and health equity, together with access to resources, education, political participation as well as a decent living standard, are all important social justice components of human existence in our pursuit for fairness, liberty and equality. Unless there is good health and health equity, people's choice and freedom would be limited and their functioning in the society would be constrained.

Sen and others argue that the most detrimental constraints on people's doing and being are imposed on them by social environments and institutional arrangements in the society. Our examination of the health divide in China's urban vs. rural sectors and among the three geographic regions has provided further evidences to this assertion. China's desire to improve its economy since the reform, as well as China's historical patterns in social and economic development, has resulted in severe and persistent health inequities. Urban population live a significantly longer life compared with rural population, and people in the coastal region are much healthier 
compared with those in the inland and western regions. Due to the interacting relationships of urban vs. rural sectors and the regional differences, the hierarchical pattern of population health is such that urban areas in the coastal region are the healthiest and the rural population in the western region, which includes most of China's ethnic minority populations, is the least healthy.

Consistent with literature on health research, our study has demonstrated that economic development and income differences between urban and rural areas and among the regions, albeit important, are by no means the only significant factors that affect the difference in health. Population health in China reflects the multi-dimensional societal arrangements that include social, cultural, political and many other institutional establishments and dynamics. The economic reform in China in the last three decades and the many policies and changes that have resulted from the reform are bound to generate long-lasting consequences to life and health of populations in China. In our attempts to present a holistic picture of variations of health in China, we have focused on two macro-level issues that reflect China's policy orientations in the social and economic development since the reform. One is the level of development of non-agricultural economy in rural areas and the other one is the extent to which urban reform, particularly the reform of state-owned enterprises, has been carried out. We hypothesize that when viewed in a broad sense, these two elements are indicators of social changes that accompany not only economic development, but also the level of development of communities, the degree of sophistication of social and cultural environment, the extent to which cities and urban areas are civilized, the amount of resources and opportunities that are available to residents and their communities, etc. All these conditions are prerequisites for the improvement of public health.

We also discussed issues of medical expenditure and the cost of medicine and health facilities, and have demonstrated that these two factors that directly affect public health are closely related to the economic development and well being of regions and areas in China. The consequence of all these combined factors determines the capacity of being and doing of individuals. In China, this could simply be a matter of whether they are urban residents or rural dwellers, and which region they happen to live in. Indeed, as Sen has pointed out, health is not an isolated issue, rather, it is one of the many components of a whole set of elements that reflect individuals' and communities' wellbeing and status.

Future research is needed also to investigate the exact and full extent of mechanisms through which social and institutional arrangements proposed above cause the variation in health in China. In addition, researchers need to continue exploring additional issues at structural and institutional levels that may determine population's health. One example of such issues is the phenomenon of the "feminization of agriculture" whereby farming in many parts of China's rural areas is attended by women with children and the elderly while young men and women look for temporary jobs as migrant workers in urban and economically advanced areas. Such family arrangements and the concurrent social and economic consequences are bound to compromise health and well-being of all the people who are involved.

\section{References}

Adams, Vincanne. (2006). Equity of the Ineffable: Cultural and Political Constraints on Ethnomedicine as a Health Problem in Contemporary Tibet, in Sudhir Anand, Fabienne Peter and Amartya Sen (eds.) Public Health, Ethics, and Equity. Oxford University Press.

Anand, Sudhir. (2006). The Concern for Equity in Health, in Sudhir Anand, Fabienne Peter and Amartya Sen (eds.) Public Health, Ethics, and Equity. Oxford University Press.

Anson, Ofra and Shifang Sun. (2005). Health Care in Rural China, Lessons from HeBei Province. Ashgate.

Bloom, Gerald and Shenglan Tang (eds.). (2004). Health Care Transition in Urban China. Ashgate.

China Health Statistical Yearbook. (2007). Beijing: China Xiehe Medical University Press.

China Human Development Report. (2007). Development with Equity. Beijing: China Translation and Publishing Corporation.

China Statistical Yearbooks. (1998, 2001, 2005 and 2007). Beijing: China Statistics Press.

Daniels, Norman, Bruce Kennedy and Ichiro Kawachi. (2006). Health and Inequality, or Why Justice is Good for Our Health, in Sudhir Anand, Fabienne Peter and Amartya Sen (eds.) Public Health, Ethics, and Equity. Oxford University Press. Pp. 63-91.

Fan, C. Cindy and Mingjie Sun. (2008). Regional Inequality in China, 1978-2006. Eurasian Geography and Economics, 49(1): 1-18. 
Gu, Chaolin, Shen Jianfa and Yu Taofang. (2004). Urban and Regional Development, in Yeung, Y.M. and Shen Jianfa (eds.). Developing China's West, a Critical Path to Balanced National Development. Hong Kong: The Chinese University Press. Pp. 177-211.

Larus, Elizabeth Freund. (2005). Economic Reform in China, 1979-2003, the Marketization of Labor and State Enterprises. Lewiston, NY: The Edwin Mellen Press.

Liu, Yuanli, Keqin Rao, Timothy Evans, Yude Chen, and William Hsiao. (2001). China: Increasing Health Gaps in a Transitional Economy, in Timothy Evans, Margaret Whitehead, Finn Diderichsen, Abbas Bhuiya and Meg Wirth (eds.) Challenging Inequalities in Health, From Ethics to Action. Oxford University Press.

Liu, Yuanli, Keqin Rao and Shanlian Hu. (2002). People's Republic of China: Toward Establishing A Rural Health Protection System. Asian Development Bank.

Marmot, Michael. (2006). Social Causes of Social Inequalities in Health, in Sudhir Anand, Fabienne Peter and Amartya Sen (eds.) Public Health, Ethics, and Equity. Oxford University Press.

Peter, Fabienne. (2006). Health Equity and social justice, in Sudhir Anand, Fabienne Peter and Amartya Sen (eds.) Public Health, Ethics, and Equity. Oxford University Press.

Restall, Hugo. (2008). The Lessons from 30 Years of Chinese Reform. Wall Street Journal, NY: New York. Dec. 16 2008. P. A. 23.

Riley, Nancy E. (2004). China's Population: New Trends and Challenges. Population Bulletin. PRB.

Robert, Stephanie A. (1998). Community-Level Socioeconomic Status Effects on Adult Health. Journal of Health and Social Behavior, 39 pp. 18-37.

Sen, Amartya. (1998). Mortality as an Indicator of Economic Success and Failure. The Economic Journal, 108(446) pp. 1-25.

------, (2006), “Why Health Equity?”, in Sudhir Anand, Fabienne Peter and Amartya Sen (eds.) Public Health, Ethics, and Equity. Oxford University Press.

Siegrist, Johannes. (2000). The Social Causation of Health and Illness, in Gary L. Albrecht, Ray Fitzpatrick and Susan C. Scrimshaw (eds.) The Handbook of Social Studies in Health \& Medicine. Sage Publications Ltd.

Song, Hongyuan. (2008). Zhonggua nongcun gaige sanshi nian (Thirty Years of China's Rural Reform). China Agricultural Publisher.

Wagstaff, Adam, Magnus Lindelow, Shiyong Wang and Shuo Zhang. (2009). Reforming China's Rural Health System. Washington, D.C. The World Bank.

Wilkes, Andreas, Yu Hao, Gerald Bloom and Gu Xingyuan. (1997). Coping with the Costs of Severe Illness in Rural China, IDS (Institute of Development Studies) Working Paper 58.

Wilkinson, Richard. (2002). The Epidemiologic Transition: From Material Scarcity to Social Disadvantage? in Frank Trovato (ed.) Population and Society, Essential Readings. Oxford University Press.

Wilson, William. (1987). The Truly disadvantaged: The Inner City, the Underclass, and Public Policy. Chicago, IL: University of Chicago Press.

Wu, Xiaogang. (2002). Work Units and Income Inequality: the Effect of Market Transition in Urban China. Social Forces, (80)3:1069-1099.

Yao, Shujie, Zongyi Zhang and Lucia Hanmer. (2004). Growing inequality and poverty in China. China Economic Review, (15)2: 145-163. 
Table 1. Health and Medical Indicators for the Population in China, 2000 and 2005

\begin{tabular}{|c|c|c|c|c|c|c|}
\hline Province/Region & Life Ex & LE Urb & LE Rur & UrMed & RuMed & RatMe \\
\hline & $1 *$ & $2 *$ & 3* & $4 *$ & $5 *$ & $6 *$ \\
\hline Beijing $^{\wedge}$ & 76.85 & 77.96 & 73.93 & 1295 & 504 & 2.5 \\
\hline Tianjin^ & 75.96 & 76.55 & 74.64 & 996 & 179 & 5.5 \\
\hline Hebei $^{\wedge}$ & 72.63 & 75.40 & 71.78 & 642 & 134 & 4.7 \\
\hline Shanxi> & 72.15 & 75.28 & 70.82 & 538 & 102 & 5.2 \\
\hline I.Mongolia> & 70.73 & 74.05 & 68.79 & 533 & 176 & 3.0 \\
\hline Liaoning ${ }^{\wedge}$ & 74.35 & 76.11 & 72.62 & 751 & 233 & 3.2 \\
\hline Jilin $>$ & 73.26 & 75.00 & 71.76 & 675 & 193 & 3.4 \\
\hline Heilongjiang $>$ & 74.28 & 76.33 & 72.32 & 613 & 253 & 2.4 \\
\hline Shanghai^ $^{\wedge}$ & 79.05 & 79.36 & 77.07 & 796 & 561 & 1.4 \\
\hline Jiangsu $^{\wedge}$ & 75.58 & 78.10 & 74.00 & 579 & 198 & 2.9 \\
\hline Zhejiang $^{\wedge}$ & 75.10 & 77.22 & 73.49 & 831 & 415 & 2.0 \\
\hline Anhui> & 72.97 & 77.23 & 71.65 & 400 & 133 & 3.0 \\
\hline Fujian $^{\wedge}$ & 74.26 & 77.08 & 72.53 & 478 & 154 & 3.1 \\
\hline Jiangxi $>$ & 70.19 & 73.53 & 69.09 & 326 & 154 & 2.1 \\
\hline Shandong $^{\wedge}$ & 74.02 & 75.94 & 72.97 & 579 & 188 & 3.0 \\
\hline Henan $>$ & 73.00 & 76.49 & 72.13 & 472 & 123 & 3.8 \\
\hline Hubei> & 72.72 & 76.50 & 70.56 & 499 & 135 & 3.6 \\
\hline Hunan $>$ & 72.63 & 75.97 & 71.53 & 601 & 168 & 3.5 \\
\hline Guangdong^ & 74.96 & 76.57 & 73.34 & 704 & 203 & 3.4 \\
\hline Guangxi> & 73.59 & 77.73 & 72.26 & 466 & 123 & 3.7 \\
\hline Hainan $^{\wedge}$ & 75.75 & 78.56 & 74.25 & 351 & 93 & 3.7 \\
\hline Chongqing\# & 71.96 & 77.13 & 69.87 & 629 & 142 & 4.4 \\
\hline Sichuan\# & 71.94 & 78.24 & 70.13 & 442 & 144 & 3.0 \\
\hline Guizhou\# & 66.62 & 73.90 & 64.74 & 403 & 71 & 5.6 \\
\hline Yunnan\# & 66.37 & 72.44 & 64.89 & 663 & 122 & 5.4 \\
\hline Tibet\# & 65.81 & 75.88 & 64.34 & 338 & 44 & 7.6 \\
\hline Shaanxi\# & 71.11 & 75.88 & 69.29 & 605 & 165 & 3.6 \\
\hline Gansu\# & 68.82 & 75.48 & 67.16 & 492 & 114 & 4.3 \\
\hline Qinghai\# & 68.78 & 77.31 & 65.79 & 554 & 152 & 3.6 \\
\hline Ningxia\# & 71.96 & 76.30 & 70.35 & 535 & 198 & 2.7 \\
\hline Xinjiang\# & 72.26 & 78.07 & 69.75 & 499 & 169 & 2.9 \\
\hline Nation & 72.56 & 75.21 & 69.55 & 601 & 168 & 3.5 \\
\hline
\end{tabular}

Notes:

$1 *$ : Life expectancy for population in China, 2000

$2 *$ : Life expectancy for urban population in China, 2000

$3^{*}$ : Life expectancy for rural population in China, 2000

$4^{*}$ : Per capita medical expense (yuan) for urban population in China, 2005

5*: Per capita medical expense (yuan) for rural population in China, 2005

$6^{*}$ : Urban/rural ratio of per capita medical expense in China, 2005

$\wedge$ : Coastal Region

$>$ : Central Region

\#: Western Region

Sources: Data for life expectancy are from China Human Development Report 2005

Data for medical expenses are from China Health Statistical Yearbook 2007 
Table 2. Employment Related Indicators in Rural and Urban Areas.

A. Rural Employment in Village and Township Industrial Enterprises (\%), 1997 to 2004

$\begin{array}{lllll} & \text { China } & \text { East } & \text { Central } & \text { West } \\ 1997 & & & & \\ 2000 & 19.92 & 34.8 & 18.23 & 9.8 \\ 2004 & 29.48 & 42.28 & 29.52 & 15.37 \\ & 28.45 & 52 & 25 & 19\end{array}$

Sources: China Statistical Yearbooks, 1998, 2001 and 2005

B. Urban Employment in State-Owned and Private Enterprises (\%), 2000 and 2006

China East Central West

State-Owned

$\begin{array}{lllll}2000 & 57.67 & 51.38 & 56.78 & 65.43 \\ 2006 & 38.86 & 29.52 & 42.9 & 44.9\end{array}$

Private

$\begin{array}{lllll}2000 & 6.6 & 8.75 & 5.12 & 5.75 \\ 2006 & 19.53 & 25.56 & 14.95 & 17.48\end{array}$

Sources: China Statistical Yearbook, 2001 and 2007.

Table 3. GDP Per Capita of China and the Three Regions, 1952-2006

$\begin{array}{llllll} & 1952 & 1978 & 1990 & 2000 & 2006 \\ \text { National } & 100 & 100 & 100 & 100 & 100 \\ \text { Coastal } & 107.68 & 126.71 & 134.91 & 147.18 & 172.75 \\ \text { Central } & 109.66 & 90.22 & 83.62 & 77.68 & 70.32 \\ \text { West } & 77.77 & 76.62 & 73.30 & 60.87 & 61.64\end{array}$

Source: Data for 1952-2000 are from Gu et al. 2004, p. 184. Data for 2006 are calculated from data in China Statistical Yearbook 2007. 
Table 4. Selected Social and Economic Variables of China and Its Regions, 2000 (unless otherwise indicated)

$\begin{array}{lllll} & \text { China } & \text { Coastal } & \text { Central } & \text { West } \\ & & & & \\ \text { Urban Population (\%)* } & 36.2 & 46.1 & 33.0 & 28.7 \\ \text { GDP Per Capita (PC) (RMB)* } & 7,701 & 11,334 & 5,982 & 4,687 \\ \text { P/C Income, Urban (RMB)* } & 6,554 & 7,929 & 5,191 & 5,642 \\ \text { P/C Income, Rural (RMB)* } & 2,367 & 3,200 & 2,071 & 1,691 \\ \text { Ratio, Urban/Rural P/C Income } & & & & \\ \text { 2000* } & 2.79 & 2.47 & 2.50 & 3.33 \\ \text { 2006\# } & 3.30 & 2.58 & 2.92 & 3.77 \\ & & & & \\ \text { Life Expectancy (LE) } & 71.4 & 75.31 & 72.74 & 69.67 \\ \text { Life Exp. Urban } & 76.37 & 77.03 & 76.1 & 76.03 \\ \text { Life Exp. Rural } & 69.55 & 73.64 & 71.57 & 68.11 \\ \text { Ratio, Urban/Rural LF } & 6.82 & 3.39 & 4.6 & 7.92\end{array}$

Medical/Health-Care Expenses (yuan), 2005

$\begin{array}{lllll}\text { Urban } & 601 & 727 & 512 & 516 \\ \text { Rural } & 168 & 260 & 156 & 132 \\ \text { Urban/Rural Ratio } & 3.57 & 2.79 & 3.28 & 3.90\end{array}$

Utilization of Hospital Beds (\%) (2006) $73.8 \quad 76.6 \quad 68 \quad 68.3$

Percent of Rural Population

with Running Water (2006)

$\begin{array}{llll}61.1 & 78.6 & 53.7 & 51\end{array}$

Percent of Rural Households with

$\begin{array}{lllll}\text { Sanitary Toilets (2006) } & 55 & 63.9 & 57.1 & 40.4\end{array}$

Source: Data marked with * are based on Gu et al. 2004, p. 192. Data marked with \# are calculated from data in China Statistical Yearbook 2007. Data on life expectancy are based on China HDR 2005 and China Statistical Yearbook 2007. The remaining data are based on China Health Statistical Yearbook 2007. 